\title{
Mudanças Tecnológicas \\ e suas Implicações na Política \\ de Formação do Professor
}

\author{
Alda Maria Duarte Araújo Castro
}

\section{Resumo}

artigo discute as transformações ocorridas no mundo do trabalho, provocadas pela globalização da economia, pelas inovações tecnológicas e pela reestruturação produtiva, procurando evidenciar o impacto dessas transformações no perfil dos trabalhadores e, conseqüentemente, nos processos formativos. Em especial, o artigo enfoca a influência dessa nova lógica do mercado na política de formação de professores da educação básica. Para tanto, tomou-se, como referência, os documentos oficiais, entre eles, Referenciais para Formação de Professores, elaborado pelo Ministério da Educação e Cultura e o Parecer n 09/2001, do Conselho Nacional de Educação, que trata das Diretrizes Curriculares Nacionais para a Formação de Professores da Educação Básica, nos quais fica evidente a necessidade de mudar os modelos tradicionais de formação para se ajustar às novas demandas do mercado, utilizando, para isso, modelos formativos mais modernos e flexíveis. Na análise dos documentos, privilegiam-se dois eixos considerados fundamentais para a formação do professor nesse novo cenário: a formação reflexiva e a formação por competência, os mesmos estão articulados com as exigências empresariais e dos organismos internacionais, que acreditam em uma formação mais prática e instrumental capaz de promover a meIhoria da qualidade da educação básica.

Palavras-chave: Mudanças tecnológicas. Política de formação. Professor reflexivo. Formação por competências.

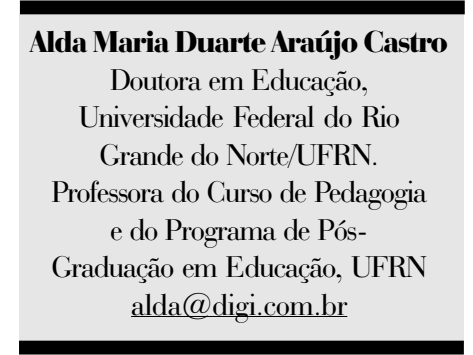

Abstract Technological Changes and it Implications on the Teachers Formation Policy

The article discusses the transformations occurred in the labor world, caused by the economy globalization, the technological innovations and by the productive restructuring, focusing on the impact of these transformations on the workers profile and, consequently, on the formative processes. The article focuses specially on the influence of the new market logics on 
the basic education teachers formation policy. Therefore, it takes as references official documents such as "Referenciais para Formação de Professores", elaborated by the Ministry of Education and Culture, and "Parecer n'. 9/2001", by the National Education Council, which discusses the National Curricular Guidelines for the Formation of Basic Education Teachers. Such documents evidence the necessity of changing the traditional models of formation to fit the new market demands, using, for this, more flexible and modern formative models. The analysis of the documents privileges two points that are considered fundamental for the teachers formation in this new scenario: the reflexive formation and the formation by competencies. Both are articulated with the demands of companies and international organisms, which believe in a more practical and instrumental formation, capable of promoting the improvement of the basic education quality.

Keywords: Technological changes. Formation policy. Reflexive teacher. Formation by competencies.

\section{Resumen}

\section{Cambios Tecnológicos}

y sus Implicaciones en la Política de Formación del Profesor

El artículo trata de los cambios ocurridos em el mundo laboral, provocados por la globalización de la economía, por las innovaciones tecnológicas y por la reestructuración productiva, buscando evidenciar el impacto de esas transformaciones en el perfil de los trabajadores y, consecuentemente, los procesos formativos. En especial, el artículo enfoca la influencia de esa nueva lógica del mercado en la política de formación de profesores de educación básica. Para eso, se tomó, como referencia, los documentos oficiales, entre ellos, Referencias para la Formación de Profesores, elaborado por el Ministerio de Educación y Cultura y el Parecer $n^{\circ}$. 9/2001, del Consejo Nacional de Educación, que trata de las directrizes Curriculares Nacionales para la Formación de Profesores de Educación Básica, em los cuales queda evidente la necesidad de cambiar los modelos tradicionales de formación para ajustarse a las nuevas demandas del mercado, usando, para eso, modelos formativos más modernos y flexibles. En la análise de los documentos se privilegian dos ejes considerados fundamentales para la formación del profesor en esse nuevo escenario: la formación reflexiva y la formación por competencia, los mismos están articulados con las exigencias empresariales y de los organismos internacionales, que creen en una formación más práctica e instrumental como capazes de promover la mejoría de la calidad de la educación básica.

Palabras clave: Cambios tecnológicos. Política de formación. Profesor reflexivo. Formación por competencias.

\section{Introdução}

As mudanças ocorridas na sociedade atual, ocasionadas pela globalização da economia, pelo desenvolvimento das tecnologias da comunicação e da informação, provocaram transformações nos diferentes campos econômicos, sociais e culturais, trazendo novos desafios para o mercado de 
trabalho. A reestruturação do capitalismo empreendida desde meados de 1970 - induziu mudanças qualitativas tanto nos planos produtivos, nos novos padrões de gestão e de organização de trabalho, quanto no plano político-econômico, com a predominância do ideário neoliberal, que coloca o mercado como instância reguladora.

Essa conjuntura criou condições para o surgimento de paradigmas econômicos mais flexíveis que vêm substituindo os modelos taylorista/fordista, numa tentativa de responder a novas configurações assumidas pelas economias internacionais. Para autores como Harvey (1992) e Anderson (1995), as inúmeras transformações que estão ocorrendo na esfera da produção, do mercado e do Estado fazem parte de um mesmo movimento histórico em que o capitalismo lança mão de novas estratégias para sobreviver.

A nova base material da produção criou as condições necessárias para que o processo de trabalho se modifique e passe a exigir uma produção de conhecimento cada vez maior e mais rápida, mais flexível, atingindo todos os setores sociais. As modernas e sofisticadas tecnologias não substituem a força de trabalho, mas dependem de uma mão-de-obra cada vez mais qualificada e bem treinada. $\bigcirc$ desenvolvimento de habilidades cognitivas e comportamentais assume papel fundamental nesse processo. Por outro lado, cresce a necessidade de trabalhar em grupo, gerenciar processos, eleger prioridades e criticar propostas. Esses são alguns dos pré-requisitos exigidos para o novo profissional.
Essa posição é reforçada por Machado (1998) ao analisar o modelo de automação flexível e sua conseqüência para a força de trabalho. Para a autora, um novo perfil de qualificação é definido para o trabalhador, exigindo: escolaridade básica, capacidade de adaptação a novas situações, compreensão de tarefas complexas, atenção e responsabilidade, atitude de abertura para novas aprendizagens, criatividade e capacidade de comunicação grupal.

Diante da necessidade e do desafio de construir um projeto de sociedade, em um mundo em acelerada mudança nas relações sociais e de trabalho, com novas exigências de qualificação para o mercado e preocupação com a cidadania, a educação emerge como um dos fatores relevantes.

Nesse sentido, a política educacional busca correlacionar educação, desenvolvimento e trabalho, ressuscitando a teoria do "capital humano"1. Essa visão economicista da educação associada à idéia de que a educação melhora o desempenho no trabalho e de que sua expansão potencializa o crescimento é bastante questionada por Frigotto (1993), que a vê como um desdobramento dos postulados da teoria econômica marginalista, aplicados à educação e como forma de aumentar o controle sobre o trabalhador e o processo de trabalho.

Nessa (re) significação da teoria do capital humano, a política governamental traz para o foco central a educação como forma de integrar as sociedades cada vez mais ao processo produtivo. Assim, privi-

\footnotetext{
' Essa teoria procura explicar o investimento em educação, como potencializadora do aumento da capacidade de trabalho e de produção. Ou seja, a produtividade do indivíduo depende da maior ou menor quantidade de capital humano que ele detiver. Maiores esclarecimentos, consultar Schultz (1973).
} 
legia o professor como protagonista central desse processo, que passa a ser uma peça-chave na reforma do sistema de ensino. No entanto, formados em rígidos paradigmas educacionais que privilegiam um modelo de formação baseado na racionalidade técnica ${ }^{2}$ na qual, inevitavelmente, se dá a separação pessoal e institucional entre a investigação e a prática, os professores têm dificuldade de se adaptar aos novos desafios do mundo do trabalho.

Discutindo sobre o modelo de formação de professores adotado ao longo da história dos processos formativos, Kuenzer (2000, p. 166) assim se posiciona:

É preciso compreender que a cada etapa de desenvolvimento social e econômico correspondem projetos pedagógicos, aos quais correspondem perfis diferenciados de professores, de modo a atender às demandas dos sistemas social e produtivo com base na concepção dominante. A primeira questão a elucidar diz respeito às mudanças ocorridas no mundo do trabalho e suas decorrências para a educação e para a formação do professor.

Nesse novo cenário, a pedagogia dominante nos modelos tayloristas/ fordistas que tinha como intenção atender às demandas educacionais dos trabalhadores e dirigentes numa concepção clara da definição de fronteiras entre as ações intelectuais e instrumentais, em decorrência de relações de classes bem demarcadas que determinavam o lugar e as atribuições de cada um, não responde mais às exigências do mundo do trabalho.

Esse modelo de pedagogia definiu um perfil de professor cujas habilidades em eloqüência se sobrepunha à rigorosa formação científica, pois era suficiente compreender e transmitir bem o conteúdo escolar que compunha o currículo, manter o respeito e a boa disciplina, requisitos básicos para a atenção e que garantiam a eficácia da transmissão.

Com a globalização da economia e com a reestruturação produtiva, esse paradigma muda significativamente. A mudança da base eletrônica para a base microeletrônica passa a exigir o desenvolvimento de habilidades cognitivas e comportamentais, próprias de ser desenvolvidas nas escolas, tais como: análise, síntese, criatividade, raciocínio lógico, interpretação e uso de diferentes formas de linguagem, necessárias para adaptação dos jovens às variações de funções que passaram a compor o mundo do trabalho.

Na ótica empresarial, tem prevalecido o entendimento de que os novos perfis profissionais e os modelos de formação exigidos atualmente pelo paradigma da produção capitalista podem ser expressos, resumidamente, em dois aspectos: polivalência e flexibilidade ${ }^{3}$. Essas características estariam postas para os trabalhos de todos os

\footnotetext{
2 Segundo Perez Gómez (1995), no modelo de racionalidade técnica, a atividade do profissional é, sobretudo instrumental, dirigida para a solução de problemas mediante a aplicação rigorosa de teorias e técnicas científicas. Trata-se de uma concepção epistemológica da prática, herdada do positivismo, que prevaleceu ao longo de todo o século XX, servindo para a educação e socialização dos profissionais em geral e dos docentes em particular.

Para Machado (1998) a polivalência se apóia no uso cientificista da ciência sujeitando o conhecimento à mera instrução utilitarista e o trabalhador a processos de adaptação definidos por regras prescritas com anterioridade. Para Cabral Neto (2004) a flexibilidade dos currículos evidencia-se na maneira de construir uma estrutura curricular que permita incorporar outras formas de aprendizagem e formação presente na realidade social. [...] Com essa abordagem a flexibilização curricular substitui o modelo de grade por uma nova estrutura que permite
} 
ramos e atividades e incluiria a identificação de habilidades cognitivas e de competências sociais requeridas no exercício das diferentes profissões. Isso requer o repensar dos perfis profissionais e dos programas de formação, qualificação e requalificação de diferentes instituições formadoras.

Esse posicionamento indica a necessidade de uma melhor qualificação da força de trabalho e identifica, também, um dos paradoxos do modelo de acumulação flexível, que quanto mais se simplificam as tarefas, mais conhecimento se exige do trabalhador e, em decorrência, aumenta o seu processo de escolaridade, levando-o a uma formação permanente. Essas novas exigências trazem conseqüências para a função da escola e, principalmente, para o professor, enquanto um dos principais agentes do processo formativo.

Analisando o novo modelo de formação, que deve ser adotado frente às mudanças ocorridas no mundo do trabalho, Kuenzer (2000) considera que, uma das primeiras características desse novo professor é compreender as mudanças ocorridas no mundo do trabalho, construindo categorias de análise que lhe permitam apreender as dimensões pedagógicas presentes nas relações sociais e produtivas, utilizando, para isso, o suporte dos conhecimentos das ciências humanas, sociais e econômicas. Outra dimensão a considerar na formação do professor é a relação que se estabelece entre homem e conhecimento a partir das novas formas de organização e gestão dos processos sociais.

Na reforma educacional, a política de formação não privilegia o modelo da sólida formação profissional proposta por
$K^{K u e n z e r}{ }^{4}$ e por outros estudiosos da temáti$\mathrm{ca}$, pelo contrário, a reforma educacional no campo da formação de professores é mediada pela ideologia do mercado e traz, como conceitos fundamentais a serem disseminados e colocados em prática, as noções de competência, habilidades, empregabilidade, competitividade, entre outras.

Essas medidas vão sendo disseminadas a partir da aprovação da Lei de Diretrizes e Bases da Educação Nacional, n. 9.394/ 96 (BRASIL, 1996), por meio de várias ações políticas e pedagógicas, tomadas no âmbito da formação com o objetivo de redirecionar o papel da educação e da escola.

\section{Políticas de formação de professores e adequação às novas exigências do mercado}

A políica de formação de professores, implementada nas últimas décadas, deve ser entendida como estratégia do denominado ajuste estrutural, que direcionou as reformas do Estado no plano político institucional e no plano econômico-adminsitrativo. Portanto, está inserida em uma perspectiva de adaptação dos profissionais às novas exigências do sistema capitalista. Na análise dos documentos oficiais, fica evidente que se está constituindo no campo da formação uma nova institucionalidade, cujas premissas ancoradas na formação por competências e na lógica que lhe é associada, possibilita a criação de novos dispositivos na gestão da formação inicial e continuada.

A reforma da formação de professores, implantada atualmente no Brasil, não é isolada. Os seus principais eixos são encontrados tanto

${ }^{4}$ KUENZER, A. As políticas de formação: a construção... Educação e Sociedade, Campinas, SP, v. 20, n. 68, dez. 2000. 
nos países desenvolvidos como em países em desenvolvimento, pois são elaborados seguindo as orientações dos organismos multilaterais de financiamento. Esses eixos foram discutidos nas diferentes conferências mundiais de educação realizadas, como as de Jomtien (1990) e Dakar (2000), e estão expressas em documentos expedidos pelos organismos internacionais como o Banco Mundial, a Organização das Nações Unidas para a Educação, Ciência e Cultura - UNES$\mathrm{CO}$-, a Organização de Cooperação e Desenvolvimento Econômico - OCDE - , e a Comissão Econômica para América Latina - CEPAL.

No Brasil, essas diretrizes foram configuradas principalmente nos seguintes documentos: Plano Decenal de Educação (1993-2003), Planejamento Político Estratégico (19951998), Lei de Diretrizes e Bases da Educação n 9.394/96 (BRASIL, 1996) e no Plano Nacional de Educação (BRASIL, 2001).

No entanto, somente após a aprovação da Lei de Diretrizes e Bases, n 9.394/96 (BRASIL, 1996), essas ações que visavam à reforma da formação dos professores foram fortemente implementadas por meio de Pareceres, Resoluções e outros documentos oficiais, que procuraram dar "uma nova feição" às práticas da formação. Para Mello (2004), era necessário promover uma (re) visão radical nas formações realizadas pelas universidades, pois são muito conteudistas e desarticuladas com a realidade.

A reforma na formação dos professores expressa uma preocupação básica a respeito do papel que esses profissionais devem desempenhar no mundo de hoje. $\bigcirc$ movimento internacional tem indicado algumas dimen- sões que vêm contribuindo para compor o modelo arquitetônico da formação de professores. Entre eles, serão destacados nesse artigo: a) a formação como uma prática reflexiva e b) a formação de competências como eixo nuclear da formação de professores.

\section{A formação reflexiva como eixo metodológico da formação do professor}

O discurso da reforma educacional define a "prática reflexiva" como modelo adequado para atender às novas exigências do mercado de trabalho. Esse modelo traz para o professor um novo perfil: ser mais participativo e ter mais autonomia para decidir sobre a sua atuação no cotidiano escolar; dessa forma, é incorporado pelo discurso oficial do MEC e amplamente divulgado pelo documento intitulado Referenciais para Formação de Professores (BRASIL, 1998). $O$ documento coloca a necessidade de redimensionar o papel do professor e da formação profissional, tomando, como referência, o Relatório Jaques Delors - que indica os quatro pilares da educação para as próximas décadas - aprender a conhecer; aprender a fazer; aprender a viver junto e aprender a $\operatorname{ser}^{5}$ (grifos nossos). Essa perspectiva configura uma nova tendência para a educação escolar, redimensionando o papel dos professores e exigindo uma formação profissional diferente da atual.

A menção ao Relatório Delors, como delineador do referencial para a educação e para a formação do professor, é uma evidência do alinhamento da educação brasileira às exigências dos organismos internacionais. A tônica principal desse discurso está

${ }^{5}$ A UNESCO instaurou, em 1993, a Comissão Internacional sobre a Educação para o Século XXl com o objetivo de identificar as tendências da educação nas próximas décadas, e, em 1996, divulgou seu relatório conclusivo. O documento ficou conhecido como Relatório Jacques Delors. 
no aprender, enfatizada exatamente porque esses organismos acreditam na centralidade do conhecimento como peça-chave no desenvolvimento sustentável das nações.

O documento Referenciais para Formação de Professores (BRASIL, 1998) reconhece a necessidade de uma formação de qualidade para o professor, sob pena de persistir o grave quadro caótico da educação brasileira. Assim, o perfil do atual professor incorporaria as tendências de formação para um professor reflexivo. Na visão do documento, a formação precisa intencionalmente possibilitar o desenvolvimento do professor como pessoa, como profissional e como cidadão.

Para isso, há o reconhecimento da necessidade de mudar o atual referencial teórico da formação, sair de um referencial técnico-instrumental para um referencial que priorize a complexidade e as singularidades da prática docente, considerando que o trabalho educacional ocorre sempre em situações específicas. Esse é o posicionamento encontrado no documento Referenciais para Formação de Professores (BRASIL, 1998, p. 59): "[...] a realidade educativa em que o professor atua é complexa, mutável, freqüentemente conflituosa, e apresenta problemas que não são facilmente categorizáveis e nem sempre possibilitam soluções a priori."

Nesse sentido, o êxito do professor depende de sua capacidade de manejar a complexidade da ação educativa e resolver problemas, por meio de uma interação inteligente e criativa.
Analisando a formação centrada na reflexão sobre a prática, Perez Gómez (1998, p. 369) chama atenção para o conceito de reflexão que deve fundamentar uma proposta para a formação reflexiva do professor, no seu entender,

A reflexão implica a imersão consciente do homem no mundo de sua experiência, um mundo carregado de conotações, valores, intercâmbios simbólicos, correspondências afetivas, interesses sociais e cenários políticos. A reflexão, ao contrário de outras formas de conhecimento, supõe um sistemático esforço de análise, como a necessidade de elaborar uma proposta totalizadora, que captura e orienta a ação. O conhecimento acadêmico, teórico, científico ou técnico só pode ser considerado instrumentos dos processos de reflexão quando for integrado significativamente, não em parcelas isoladas da memória semântica, mas nos esquemas de pensamento mais genéricos que o indivíduo ativa ao interpretar a realidade concreta em que vive e sobre a qual atua, e quando organiza sua própria experiência.

Portanto não é qualquer conceito de reflexão que deve oferecer sustentação a uma proposta de formação de professor reflexivo, sob pena de limitar essa formação a uma reflexão técnica, preocupada com a eficiência e eficácia dos meios para atingir determinados fins e com a teoria como meio para previsão e controle. Apesar da idéia do professor reflexivo se apresentar como recente e incorporar o referencial para a formação do professor no contexto da reforma educacional da década de noventa, é importante ressaltar que as origens dessa perspectiva de formação de professores remontam a Dewey ${ }^{6}$.

\footnotetext{
${ }^{6}$ A idéia do professor, enquanto prático reflexivo, encontra respaldo nas idéias de John Dewey (1967). $\bigcirc$ autor defende a idéia do aprender fazendo, aprender através da experiência. Dewey, citado por Toschi (1999), faz uma diferenciação entre os atos de rotina e atos reflexivos, e foi o conceito de reflexão que serviu como pano de fundo para os estudos de Schön (1995) e posteriormente de Zeichner (1993). O ato de rotina é guiado pelo impulso, tradição e autoridade e os atos não empreendem ruptura. A ação reflexiva é uma maneira de encarar e responder os problemas, uma maneira de ser do professor. A ação reflexiva também é um processo que implica mais do que a busca de soluções lógicas e racionais para os problemas. A reflexão implica intuição, emoção e paixão; não é, portanto, nenhum conjunto de técnicas que possa ser empacotado e ensinado aos professores, como alguns tentaram fazer.
} 
Na atualidade, Schön (1995) foi, sem dúvida, um dos autores com maior influência na difusão do conceito de professor como prático reflexivo. Essa concepção tem em comum o desejo de superar a relação linear e mecânica entre o conhecimento científico-técnico e a prática de sala de aula. A análise de Schön é uma análise mais centrada no cotidiano da escola, na relação professor-aluno.

Para o autor ${ }^{7}$, o professor reflexivo não privilegia o saber escolar (esse entendido como um tipo de conhecimento que os professores, supostamente, possuem e transmitem aos alunos) mas sim os "saber tácito" dos alunos, espontâneo, intuitivo, experimental, o conhecimento cotidiano. Para que o professor se familiarize com esse tipo de saber,

tem de lhe prestar atenção, ser curioso, ouvi-lo, surpreender-se e actuar como uma espécie de detetive que procura descobrir as razões que levam as crianças a dizer certas coisas. Este tipo de professor tem de esforçar-se por ir ao encontro do aluno e entender o seu próprio processo de conhecimento, ajudando-o a articular o seu conhecimento-na-ação com o saber escolar. Este tipo de ensino é uma forma de reflexão-na-ação que exige do professor uma capacidade de individualizar, isto é, de prestar atenção a um aluno, mesmo numa turma de trinta, tendo a noção do seu grau de compreensão e das suas dificuldades (SCHÖN, 1995, p. 82).

autor considera diferentes categorias para descrever uma epistemologia da prática: "conhecimento na ação", refere-se ao saber fazer; "reflexão na ou durante a ação", refere-se aos processos de pensamento realizados no decorrer da ação, sempre que os professores têm necessidade de reenquadrar uma situação problemática à luz da informação obtida a partir da ação; "reflexão sobre a ação e sobre a reflexão na ação", referem-se ao processo de construção do pensamento que ocorre, retrospectivamente, sobre uma situação problemática e sobre a reflexão-na-ação produzidas pelo professor. Em síntese, o professor reflexivo seria aquele que aprende a partir da análise e interpretação de sua própria atividade.

A formação do professor reflexivo, apesar de incorporar certas atitudes e predisposições pessoais nos professores, necessita, ainda, no entender de Garcia ${ }^{8}$, incorporar uma série de habilidades cognitivas e metacognitivas. Pollard e Tann (1989 apud GARCIA, 1995) enumeram essas destrezas: "empíricas" (implicam a capacidade de compilar dados, descrever situações, processos, causas e efeitos); "analíticas" ( analisar os dados compilados e a partir deles construir uma teoria); "avaliativas" (emissão de juízos); "estratégicas" (planejamento da ação); "práticas" (relacionar a análise com a prática); "comunicação" (necessidade de comunicar e partilhar as suas idéias com os colegas).

Apesar de reconhecer a importância dessas destrezas para a prática do professor, Garcia $^{9}$ não considera que elas sejam suficientes para o desenvolvimento reflexivo e toma emprestado de Dewey (1967) três atitudes que ele destaca para a constituição

\footnotetext{
${ }^{7}$ SCHON, D. A. Formar professores como profissionais reflexivos. In: NÓVOA, A. (Org.). Os professores e sua formação. Lisboa: Dom Quixote, 1995.

${ }^{8} \mathrm{GARCIA}, \mathrm{C}$. M. A formação de professores: novas perspectivas baseadas na investigação sobre o pensamento do professor. In: NÓVOA, A. (Org.). Os professores e sua formação. Lisboa: Dom Quixote, 1995.

${ }^{9}$ Id., Ibid., 1995.
} 
desse perfil: "mentalidade aberta", que se define como a ausência de preconceitos, de parcialidade, capacidade de aceitar novas idéias e reconhecer as possibilidades do erro; "responsabilidade intelectual", assumir a coerência e a harmonia daquilo que defende; "entusiasmo", afrontar a atividade com curiosidade, energia, lutar contra a rotina.

Perez Gómez (1998) entende que os estudos de Schön (1995) contribuíram, significativamente, para a construção do arcabouço do perfil da formação do professor reflexivo. Os estudos de Grimmett ${ }^{10}$, porém, avançam no sentido da construção dessa formação, quando coloca a reflexão como processo de reconstrução da experiência, que Perez Gómez vai nomear como "reflexão na prática para a reconstrução social". Para o autor:

nessa categoria agrupam-se aqueles que concebem o ensino como uma atividade crítica, uma prática social saturada de opções de caráter ético, na qual os valores que presidem sua intencionalidade devem ser traduzidos em princípios de procedimentos que dirijam e que se realizam ao longo de todo o processo de ensino-aprendizagem. $\bigcirc$ professor/a é considerado um/a profissional autônomo/a que reflete criticamente sobre a sua prática cotidiana para compreender tanto as características dos processos de ensino-aprendizagem quanto do contexto em que o ensino ocorre, de modo que a sua atuação reflexiva facilite o desenvolvimento autônomo e emancipador dos que participam do processo educativo (GRIMMET, 1989 apud PEREZ GÓMEZ, 1998, p. 373).
Nessa perspectiva, apoiamo-nos, também, nas idéias de Zeichner (1993) por trazerem um componente mais abrangente. Em primeiro lugar, o professor não deve limitar-se à reflexão, apenas, sobre a sua sala de aula mas também às condições sociais, políticas e econômicas sobre as quais a sua prática ocorre; em segundo plano, devem-se considerar as situações de desigualdade e injustiça que os alunos trazem para dentro de sua sala de aula. Por último, deve refletir sobre a prática social na construção de comunidades de aprendizagem em que os professores apóiam e sustentam o crescimento uns com os outros. No seu entendimento as experiências da prática devem ser politicamente mais ativas para que se consiga alterar e aprimorar o seu contexto estrutural.

Autores como Perez Gómez (1998) e Zeichner (1993) defendem para a formação do professor: a aquisição de uma bagagem cultural de clara orientação política e social, na qual as disciplinas humanas devem ser consideradas o eixo central da formação; o desenvolvimento de capacidades de reflexão crítica sobre a prática e o desenvolvimento de atitudes que requerem o compromisso político do professor com a possibilidade de atuar como um intelectual transformador, na aula, na escola e no contexto social.

O discurso da reforma usa o modelo de formação do professor reflexivo como adequado à formação docente. No entanto, Zeichner (1993) alerta para o uso que as reformas fazem do professor reflexivo, pois, em vez de conceder autonomia aos professores, produzem, de forma sutil, novos dis-

\footnotetext{
${ }^{10}$ Grimmett (1989), citado por Perez Gómez (1998), distingue três perspectivas diferentes de reflexão no que se refere à prática profissional: a) reflexão como ação mediatizada instrumentalmente; b) reflexão como processo de deliberação entre diversas e confrontadas orientações de ensino; c) reflexão como reconstrução da experiência.
} 
positivos de controle sobre os docentes, levando-os a uma maior dependência. Arce (2001) vai mais além, pois afirma que o referencial do professor reflexivo, utilizado no contexto da atual reforma educacional privilegiando a prática, tem levado ao desenvolvimento de uma formação pragmatista e aligeirada. A autora (ARCE, 2001, p. 262) acrescenta,

Retira-se definitivamente do professor o conhecimento, acaba-se com a dicotomia existente entre teoria e prática, eliminando a teoria no momento em que esta se reduz a meras informações; o professor passa a ser o balconista da pedagogia fast food, que serve uma informação limpa, eficiente e com qualidade, na medida em que, com seu exemplo, desenvolve no aluno (cliente) o gosto por captar informações utilitárias e pragmáticas.

Fazendo uma crítica ao professor reflexivo, adotado pelo MEC, Toschi (1999) considera que há quatro características no atual movimento reformista que minam a emancipação proposta pela idéia do professor como prático reflexivo: a avaliação dos professores, levando-os a uma melhor imitação de práticas sugeridas das investigações já realizadas; o processo reflexivo, que, na racionalidade técnica, limita-se à consideração das capacidades e estratégias de ensino; o desprezo das condições sociais do ensino; e a insistência no processo de reflexão individual e não coletivo.

Parece evidente que há um desvirtuamento dos pressupostos da formação do professor reflexivo tomado como modelo pela reforma educacional da década de noventa. Isso representa um paradoxo em termo de qualificação do professor, pois, diante da centralidade do conhecimento, o professor deveria ter uma forte formação teórica, uma considerável bagagem filosófica, histórica, social e política, para poder respaldar a sua prática, e, ainda, propor mudanças significativas na educação. Essa preocupação não está presente nas políticas de formação.

A ênfase na valorização do conhecimento produzido no cotidiano do professor e o conhecimento advindo de sua prática dão à formação do professor um caráter pragmático, respaldado no aprender fazendo e reforçam a argumentação que leva à formação aligeirada do professor.

\section{As competências como eixo da formação dos professores}

Um outro eixo da reforma educacional que tem sido utilizado como adequado para modificar os tradicionais modelos de formação de professores é o "currículo por competência", apesar de não ser uma abordagem nova, nas últimas décadas do século XX, esse aporte tem-se revestido de certa "modernidade", e classifica como ultrapassado tudo o que não cabe nesse entendimento sobre a formação do professor.

O termo competência é bastante polêmico e tem recebido vários significados. Para Nuñez e Ramalho (2002), o sentido de competência no paradigma técnico-positivista é considerado como a capacidade de aplicar os conhecimentos da ciência e da tecnologia aos problemas instrumentais da prática, o que estaria associado ao conceito de habilidade profissional. No entanto, os autores ressaltam a evolução que o termo assume no contexto atual,

na dinâmica das novas formas organizativas da política de formação profissional, o conceito de competência emerge como uma noção básica que procu- 
ra unir operativamente teoria e prática. Isto quando se assume que toda teoria tem implicações práticas e toda habilidade prática tem uma teoria, implícita ou não, que a sustenta, fazendo-se necessário conhecê-la para fundamentar o agir profissional. Essas exigências conduzem o entendimento do termo de competência para um sentido mais compreensivo do que meramente técnico (NUÑEZ; RAMALHO, 2002, p. 14).

Outros autores, entre eles, Perrenoud (1993), definem competência como faculdade de mobilizar um conjunto de recursos cognitivos para solucionar problemas. Nessa ótica, os conteúdos dos cursos de formação deixam de ter importância em si mesmos e passam a ser entendidos como meios para produzir aprendizagem e constituir competências para os professores. Esse é o entendimento oficial utilizado nos documentos do MEC, para a formação do professor, e, nessa visão, não é suficiente que o profissional tenha conhecimento do seu trabalho, mas que saiba mobilizálos, transformando-os em ação.

currículo por competência vem sendo utilizado desde as décadas de 1960 e 1970 nos Estados Unidos. Inicialmente, guardava aproximações com o Currículo por Objetivos, que defendia que a eficiência escolar poderia ser alcançada por meio do controle do trabalho docente - tese baseada nos princípios da administração científica. $\bigcirc$ currículo por objetivos apresentava um perfil de profissional a ser formado identificando as competências que o sujeito deveria demonstrar; definia esses perfis com base no desempenho desejável dos professores para garantir a eficiência do processo ensino-aprendizagem; estabelecia a eficiência do processo educacional com base nas expectativas sociais, centradas no mercado de trabalho.
Havia na ocasião uma crença determinista de que o desempenho do aluno dependia diretamente do desempenho dos professores. Esse entendimento desencadeou uma série de estudos e pesquisas, sobre a eficiência do professor. Baseado nos resultados dessas pesquisas, surgiram os modelos de formação denominados: Formação do Professor Baseado em Competências (CBTE) e Educação do professor baseado em Desempenho. Esses modelos de formação influenciaram a formação dos professores nos Estados Unidos por, pelo menos, 15 anos (DIAS; LOPES, 2003).

Atualmente, no contexto das mudanças tecnológicas, o termo competência assume o mesmo significado da noção utilizada no mundo da indústria e das empresas, e está associado às exigências dos organismos multilaterais, que defendem uma formação profissional mais flexível e polivalente para atuar em um mundo em constante evolução. Portanto, o termo vem sendo reformulado, tanto no seu sentido quanto em sua utilização e passou a fazer parte dos currículos de formação de qualquer profissional. No entendimento das organizações empresariais e dos organismos internacionais, a pedagogia das competências é a mais adequada, pois permite a construção de um perfil profissional, que atende melhor às exigências de empregabilidade do mundo contemporâneo.

Discutindo sobre as mudanças no mundo do trabalho que originou novos paradigmas para formação e colocou ênfase nas competências, Hirata (1994) alerta para o fato de que a competência é uma noção oriunda do discurso empresarial nos últimos dez anos, ainda bastante imprecisa e marcada políitica e ideologicamente por sua origem, e da qual está totalmente ausente a idéia de relação social. 
Ainda para a autora ${ }^{11}$, a adoção do modelo de formação baseado nas competências, implica um compromisso com o novo modelo de reestruturação produtiva (pós-taylorista) difícil de pôr em prática se não se verificam soluções a toda uma série de problemas, sobretudo o de um desenvolvimento não remunerado das competências dos trabalhadores na base da hierarquia.

No Brasil, o currículo por competências para a formação de professores é regulado pelo Parecer $n^{\circ}$. 9/2001 (CONSELHO NACIONAL DE EDUCAÇÃO, 2001), que estabelece as Diretrizes Curriculares Nacionais para a Formação de Professores da Educação Básica em nível superior, curso de licenciatura, de graduação plena, buscando estabelecer uma sintonia entre a formação dos professores prevista pela LDB n 9.394/96 (BRASIL, 1996) e as recomendações constantes dos Parâmetros e Referenciais Curriculares (1997) para a Educação Básica elaborada pelo MEC.

O documento descreve o contexto global e nacional da reforma educacional no Brasil, o quadro legal que lhe dá suporte e as linhas orientadoras das mudanças dos cursos de formação de professores em nível superior. Com base no diagnóstico dos problemas detectados na formação dos profissionais, apresenta princípios orientadores amplos e diretrizes para uma política de formação de professores, para sua organização no tempo e no espaço e para a estruturação dos cursos.

Apresenta, ainda, a necessidade de modificar os contextos de formação numa tentativa de acompanhar as mudanças tecnológicas e as transformações do processo produtivo. $\bigcirc$ professor, enquanto profissional que lida com a construção do conhecimento, não pode ficar à margem dessas mudanças. Apresenta como dificuldade para se conseguir a melhoria do ensino básico, o preparo inadequado dos professores cuja formação, de modo geral, manteve predominantemente um formato tradicional, que não contempla muitas das características consideradas na atualidade, como inerentes à atividade docente.

Nesse sentido, o Parecer $n^{\circ}$ 9/2001 (BRASIL, 2001, p. 23) traz o seguinte posicionamento,

Atuar com profissionalismo exige do professor, não só o domínio dos conhecimentos específicos, em torno dos quais deverá agir, mas, também, compreensão das questões envolvidas no seu trabaIho, sua identificação e resolução, autonomia para tomar decisões, responsabilidade pelas ações feitas. Requer ainda que o professor saiba avaliar criticamente a própria atuação e o contexto em que atua e que saiba, também, interagir cooperativamente com a comunidade profissional a que pertence a sociedade.

Essa forma de pensar a formação profissional do professor traz modificações em todo processo de aprendizagem e deve refletir-se na própria forma de organização da instituição, na seleção de conteúdos, na metodologia do trabalho e na forma de avaliação. Para Mello (2004), " o momento exige que se concretizem reformulações profundas nos modelos de formação inicial vigente, com o objetivo de incidir nas matrizes geradoras de maus profissionais $[. . .]^{\prime \prime}$. A autora parece colocar a culpa da má formação dos professores apenas no tipo de formação recebi-

${ }^{11}$ HIRATA, H. Da polarização das qualificações ao modelo da competência. In: FERRETTI, C. J. et al. (Org.). Novas tecnologias, trabalho e educação: um debate multidisciplinar. 4. ed. Petrópolis: Vozes, 19944. 
da por esses profissionais, esquecendo-se de questionar a ausência de uma política de valorização por parte dos organismos oficiais para os profissionais da educação e as condições de trabalho a que estão submetidas no seu dia-a-dia.

O Parecer no 9/2001 do Conselho Nacional de Educação (2001, p. 32-35) traz também explícitas as competências que devem ser desenvolvidas para a formação dos professores para a educação básica. São elas: competências referentes ao comprometimento com os valores inspiradores da sociedade democrática; competências referentes à compreensão do papel social da escola; competências referentes ao domínio dos conteúdos a serem socializados, de seus significados em diferentes contextos e de sua articulação interdisciplinar; competências referentes ao domínio do conhecimento pedagógico; competências referentes ao conhecimento de processos de investigação que possibilitem o aperfeiçoamento da prática pedagógica; competências referentes ao gerenciamento do próprio desenvolvimento profissional.

Maués (2004), apoiada nas idéias de Romainville (1995), critica o modelo de competências utilizado para a formação dos profissionais. A crítica feita pela autora reside na compreensão do termo "competência" presente no Parecer $n^{\circ}$. 9/2001. A noção presente é de que a competência para se realizar necessita de ação, ou seja, de uma atividade prática, de situações concretas e contextualizadas. No entender de Mavés, essa compreensão levaria necessariamente, a uma predominância dos conhecimentos práticos sobre os teóricos, tornando a formação superficial e pragmática. Nesse sentido, faz a seguinte colocação:

[...] na 'economia do saber' o útil, o prático é o que pode ser posto em ação de imediato, em situação. Como dizem os experts em competência. Nessa lógica alguns conhecimentos, que não são solicitados pelo mercado, como os conhecimentos de filosofia; as questões da cultura como apreciação de obras de artes, de uma literatura refinada; as análises que dependem de um conhecimento político e tantos outros certamente não serão considerados a partir desses approche, pois não serão exigidos pelo mercado, pela economia do saber (MAUÉS, 2004, p. 4).

Concordamos com a autora que a reforma educacional tem trazido para a formação de professor uma redução significativa dos conhecimentos. Outros documentos e pareceres editados pelo CNE, também têm contribuído para reduzir a carga horária dos conhecimentos científicosculturais, antes desenvolvidos nos cursos de formação inicial de professores, como a Resolução do Conselho Nacional de Educação (2002), CNE/CP n . 2, de 19 de fevereiro de 2002, que traz uma redução de carga horária para a formação do professor da educação básica.

Os documentos analisados fazem parte de uma política mais ampla que vem sendo adotada pelo MEC a partir da aprovação da LDB n 9.394/96 (BRASIL, 1996), para implantação do que se convencionou chamar a segunda geração da reforma educacional. Encontram-se, portanto, articuladas com outras ações desencadeadas pelo Ministério. $O$ Parecer do Conselho Nacional de Educação (2001, p. 4), ao analisar as ações da política de formação, reforça esse entendimento:

A Proposta de Diretrizes Nacionais para a Formação de Professores para a Educação Básica Brasileira busca também 
construir sintonia entre a formação de professores, os princípios prescritos pela Lei de Diretrizes da Educação Nacional/ LDBN, as normas instituídas nas Diretrizes Curriculares Nacionais para a Educação Infantil, para o Ensino Fundamental e para o Ensino Médio, e suas modalidades, bem como as recomendações constantes dos Parâmetros e Referenciais Curriculares para a Educação Básica elaborados pelo Ministério da Educação.

Como podemos perceber, não se trata de uma iniciativa isolada, mas de um conjunto de definições e ações que dão corpo à reforma educacional no campo da formação dos professores, buscando flexibilizar a formação, quer seja em conteúdos, quer seja na redução da carga horária se distanciando cada vez mais de uma sólida formação.

O entendimento das autoras Dias e Lopes (2003), sobre o desenvolvimento das competências, como princípio para atividade profissional defendida nos documentos do MEC, é que elas visam à aprendizagem de um "conhecimento útil" para o exercício da profissão, colocando o "foco da avaliação na capacidade de acionar conhecimentos e buscar outros, necessários à atuação profissional."

A formação por competências permite uma formação flexível, polivalente, que atende às exigências imediatas. Os cursos de formação, independente da preocupação com uma sólida formação do professor, que the dê condições de fazer uma leitura crítica do mundo, se ocupará em ensinar aquilo que terá utilidade garantida. Nesse aspecto, reside uma das grandes mudanças enfrentadas no campo da formação, os conhecimentos deixam de ser importantes para se dar maior destaque ao saber fazer. Isso significa uma redução quantitativa de conhecimentos e forma operacional de apresentá-los, tornando a formação superficial e pragmática.

\section{Considerações finais}

No capitalismo contemporâneo, o professor, como os demais trabalhadores são requisitados a repensar suas funções, para atender a um mundo em constantes transformações. Nesse sentido, as políticas educacionais têm-se direcionado cada vez mais para atender à lógica do mercado, provocando mudanças substantivas no campo da formação do professor. As ações desenvolvidas no âmbito do Ministério da Educação têm objetivado a construção de um professor com habilidades e competências, capazes de reproduzir na escola e na sua sala de aula, as novas formas de trabalho demandadas pelo nível de desenvolvimento do capitalismo na atualidade.

Os documentos oficiais, entre eles, Referenciais para formação dos professores (BRASIL, 1998) e As diretrizes curriculares para a formação de professores da educação básica (CONSELHO NACIONAL DE EDUCAÇÃO, 2001), fazem parte de um conjunto de iniciativas do governo brasileiro para regular a formação de professores aos ditames dos organismos internacionais, considerados os guardiões das reformas educacionais em todos os países da América Latina.

No que se refere especificamente às questões identificadas nesse artigo, como "a formação como prática reflexiva" e a "competência como eixo da formação", identifica-se que elas devem ser compreen- 
didas como mecanismos de ajuste da reforma estrutural, de aligeiramento, de expansão e de massificação da formação de professores em nível superior, priorizando a ótica quantitativa em detrimento da qualidade dessa formação.

Essas diretrizes, como princípio para a atividade profissional defendida nos documentos, visam à aprendizagem de um "conhecimento útil" para o exercício da profissão. A dimensão prática e reflexiva, a secundarização das tradicionais disciplinas como modelo de organização curricular, têm distorcido a formação do professor, provocando uma formação superficial, instrumental, que não contribui para a profissionalização docente.

Os "Referenciais para a formação de professor" e "As diretrizes curriculares para a formação de professores da educação básica" assumem uma concepção mais voltada à técnica, cuja ênfase está associada a situações concretas ou da experiência profissional e podem vir a resultar no esvaziamento do espaço de conteúdo dos diferentes conhecimentos em favor ao saber técnico de como desenvolver a atividade de ensino na escola a partir da valorização do desempenho, do resultado e da eficiência.
No nosso entendimento, esse modelo de formação leva a uma nova exploração do processo de trabalho, uma vez que os profissionais são estimulados a participar na gestão da produção do trabalho escolar, no trabalho em equipe e a ter um envolvimento maior nas estratégias de competitividade das organizações, sem ter, necessariamente uma compensação em termos salariais.

A amplitude que se espera do trabalho do professor parece encaminhar-se à contramão da história. A falta de uma política consistente de valorização do magistério tem levado essa carreira a uma deterioração progressiva. Deparamo-nos com uma classe totalmente desmotivada, desvalorizada, com condições de trabalho inadequadas e uma formação que não condiz com uma prática flexível, criativa e dinâmica adequada às novas exigências do mundo do trabalho.

Para que o professor possa atuar de forma competente na formação de um cidadão crítico e participativo no âmbito da sociedade, é necessário o desenvolvimento de políticas de formação que valorizem os professores enquanto profissionais, possibilitando-lhes uma formação inicial consistente e oportunidades de formação continuada que, concretamente, promovam o seu desenvolvimento profissional. 


\section{Referências}

ANDERSON, P. Balanço do neoliberalismo. In: SADER, E.; GENTILI, P. (Org.). Pósneoliberalismo: as políticas sociais e o estado democrático. Rio de Janeiro: Paz e Terra, 1995.

ARCE, A. Compre um kit neoliberal para a educação infantil e ganhe grátis os dez passos para se tornar um professor reflexivo. Educação e Sociedade, Campinas, SP, v. 22, n.74, abr. 2001.

BRASIL. Lei n. 9.394, de 20 de dezembro de 1996. Estabelece as diretrizes e bases da educação nacional. Diário Oficial [da] República Federativa do Brasil, Brasília, DF, 23 dez. 1996. Disponível em: <http://www.planalto.gov.br>. Acesso em: 10 jun. 2005.

- Ministério da Educação e do Desporto. Secretaria do Ensino Fundamental. Referenciais para formação de professores. Brasília, DF, 1998.

CABRAL NETO, A. (Org.). Flexibilização curricular: cenários e desafios. Natal, RN: EDUFRN, 2004. (Coleção pedagógica).

CEPAL. UNESCO. OREALC. Educação e conhecimento: eixo da transformação produtiva com equidade. Brasília, DF: IPEA: INEP, 1995.

CONSELHO NACIONAL DE EDUCAÇÃO (Brasil). Parecer CNP/CP n. 9/2001, de 8 de maio de 2001. Dispõe sobre as diretrizes curriculares para a formação de professores da educação básica em nível superior, curso de licenciatura, de graduação plena. Brasília, DF, 2001.

. Resolução CNP/CP n. 2, de 19 de fevereiro de 2002. Institui a duração e a carga horária dos cursos de licenciatura, de graduação plena, de formação de professores da educação básica em nível superior. Brasília, DF, 2002.

DELORS, J. et al. (Coord.). Educação: um tesouro a descobrir: relatório para a UNESCO da Comissão Internacional sobre Educação para o Século XXI. Tradução José Carlos Eufrázio. São Paulo: Brasília, DF; Cortez; UNESCO, 1998.

- La educación encierra um tesoro: informe a la UNESCO de la Comissión Internacional sobre la Educación para el siglo XXI. Madrid: Santillana: Ediciones UNESCO, 1996.

DEWEY, J. Vida e educação. São Paulo: Melhoramentos, 1967.

DIAS, R. E.; LOPES, A. C. Competências na formação de professores no Brasil: o que (não) há de novo. Educação e Sociedade, Campinas, SP, v. 24, n. 85, dez. 2003. 
FREITAS, L. C. Em direção a uma política para a formação de professores. Em Aberto, Brasília, DF, v.12, n. 54, abr./jun. 1992.

FRIGOTTO, G. Educação como capital humano: uma teoria mantenedora do senso comum. $\ln$ : . A produtividade da escola improdutiva. 4. ed. São Paulo: Cortez, 1993.

GARCIA, C. M. A formação de professores: novas perspectivas baseadas na investigação sobre o pensamento do professor. In: NÓVOA, A. (Org.). Os professores e sua formação. Lisboa: Dom Quixote, 1995.

GIMENO SACRISTÁN, J. Educação pública: um modelo ameaçado. In: GENTILI, P.; SILVA, T. T. (Org.). Escola S.A.: quem ganha e quem perde no mercado educacional do neoliberalismo. Brasília, DF: CNTE, 1996.

HARVEY, D. A condição pós-moderna. São Paulo: Loyola, 1992.

HIRATA, H. Da polarização das qualificações ao modelo da competência. In: FERRETTI, C. J. et al (Org.). Novas tecnologias, trabalho e educação: um debate multidisciplinar. 4 ed. Petrópolis: Vozes, 1994.

KUENZER, A. Z. As políticas de formação: a construção da identidade do professor sobrante. Educação e Sociedade, Campinas, SP, v. 20, n. 68, dez. 2000.

MACHADO, L. R. S. Educação e os desafios das novas tecnologias. In: FERRETI, C. J. (Org). Novas tecnologias, trabalho e educação: um debate multidisciplinar. Petrópolis: Vozes, 1998.

MAUÉS, O. As políticas de formação e a pedagogia das competências. In: REUNIÃO DA ANPED, 27., 2004, Caxambu. Sociedade democrática e educação: qual universidade? Caxambu, MG: ANPED, 2004. 1 CD-ROM.

MELLO, G. N. Educação escolar brasileira: o que trouxemos do século XX? Porto Alegre: Artmed, 2004.

NUÑEZ, I. B.; RAMALHO, B. L. Competência: uma reflexão sobre o seu sentido. In: OLIVEIRA, V. Q. S. F. (Org.). O sentido das competências no projeto políticopedagógico. Natal, RN: EDUFRN, 2002.

PARÂMETROS Curriculares Nacionais. Brasília, DF: MEC, SEF, 1997. Disponível em: < http://www.mec.gov.br/sef/estrut2/pcn/pdf/livro01.pdf>. Acesso em: 10 jun. 2005. 
PEREZ GÓMEZ, A. A função e a formação do professor/a no ensino para a compreensão: diferentes perspectivas. In: GIMENO SACRISTÁN, J.; PEREZ GOMÉZ, A. (Org.). Compreender e transformar o ensino. Porto Alegre: Artes Médicas, 1998.

pensamento prático do professor: a formação do professor como profissional reflexivo. In: NÓVOA, A. (Org.). Os professores e sua formação. Lisboa: Dom Quixote, 1995.

PERRENOUD, P. Práticas pedagógicas, profissão docente e formação: perspectivas sociológicas. Lisboa: Dom Quixote, 1993.

ROMAINVILLE, M. L'irrésistible ascencion du terme "competénce" en éducation. Revue de Didactique du Français, Paris, n. 37/38, mars/juin 1995.

SCHÖN, D. A . Formar professores como profissionais reflexivos. In: NÓVOA, A. (Org.). Os professores e sua formação. Lisboa: Dom Quixote, 1995.

SCHULTZ, T. W. O capital humano. Rio de Janeiro: Zahar, 1973.

TOSCHI, M. S. Formação de professores reflexivos e TV Escola: equívocos e potencialidades em um programa governamental de educação a distância. 1999. Tese (Doutorado em Educação) - Universidade Metodista de Piracicaba, Piracicaba, SP, 1999.

ZEICHNER, K. A formação reflexiva de professores: idéias e práticas. Lisboa: Educa, 1993.

Recebido em: 28/06/2005

Aceito para publicação em: 22/08/2005 